\title{
Important Regulatory Role of Activated Platelet-Derived Procoagulant Activity in the Propagation of Thrombi Formed Under Arterial Blood Flow Conditions
}

\author{
Noriko Tamura, MS; Isao Kitajima, MD**; Yota Kawamura, MD; Eri Toda, MD; \\ Yu Eguchi, MD; Hideyuki Ishida, MD*; Shinya Goto, MD
}

\begin{abstract}
Background: The functional links between the activation of platelets and the coagulation system have not been clarified.

Methods and Results: Immobilized collagen fibrils were perfused with human blood containing fluoresceinated platelets in the presence of various concentrations of thrombin inhibitor. Coagulant activity around platelet thrombi was detected using a FITC-conjugated antibody against the fibrin monomer complex (F-405). Intra-cytosolic calcium ion concentrations $\left(\left[\mathrm{Ca}^{2+}\right]_{i}\right)$ in individual platelets and the volume of thrombi were detected with an ultrafast confocal laser microscope equipped with a piezo-motor control unit. The volume of platelet thrombi formed after $8 \mathrm{~min}$ of blood perfusion in the presence of $10,25,50$, and $100 \mu \mathrm{mol} / \mathrm{L}$ argatroban was $7.69 \pm 0.46 \mu \mathrm{m}^{3}$, $6.61 \pm 1.96 \mu \mathrm{m}^{3}, 3.63 \pm 1.54 \mu \mathrm{m}^{3}$, and $1.67 \pm 0.75 \mu \mathrm{m}^{3}$, respectively. There was a positive correlation between the volume of platelet thrombi and the amount of fibrin monomer complex produced around them. The $\left[\mathrm{Ca}^{2+}\right] \mathrm{i}$ of the platelets forming the thrombi oscillated between a minimum of $92.0 \pm 57.4 \mathrm{nmol} / \mathrm{L}, 120.1 \pm 68.1 \mathrm{nmol} / \mathrm{L}$, and a maximum of $217.6 \pm 131.5 \mathrm{nmol} / \mathrm{L}, 367.6 \pm 189.1 \mathrm{nmol} / \mathrm{L}$, respectively, in the presence of 100 and $10 \mu \mathrm{mol} / \mathrm{L}$ argatroban.
\end{abstract}

Conclusions: The results suggest a crucial role of coagulant activity in both the generation of fibrin and the growth of platelet thrombi. (Circ J 2009; 73: 540-548)

Key Words: Blood flow; Calcium; Fibrin monomer complex; Platelet; Thrombin

$\mathbf{T}$ hrombi causing the "so-called atherothrombotic diseases"1 contain at least 3 components: platelets, fibrin, and inflammatory cells, 2,3 The functions and activation mechanisms of the platelets, 4 the coagulation cascade,, 7 and the inflammatory cells ${ }^{8}$ have been investigated extensively. Now, attention is being focused on the functional links among these components during the formation of thrombi large enough to cause symptomatic atherothrombosis $9,10-13$

Indeed, platelets adhere and accumulate at sites of endothelial damage and are known to play a central role in the local regulation of coagulation and inflammation (eg, platelets have a procoagulant membrane component on their surface upon activation, ${ }^{14,15}$ express adhesive molecules ${ }^{16}$ to capture inflammatory cells in the thrombi, release inflammatory cytokines such as the CD40 ligand ${ }^{17-19}$ and procoagulant microparticles ${ }^{20,21}$ ). Local activation of coagulation and inflammation that occurs around the activated platelets

(Received May 16, 2008; revised manuscript received October 7, 2008; accepted October 19, 2008; released online January 29, 2009)

Department of Medicine, *Department of Basic Science, Tokai University School of Medicine, Isehara and **Department of Clinical Laboratory and Molecular Pathology, University of Toyama, Toyama, Japan

Mailing address: Shinya Goto, MD, Department of Medicine, Tokai University School of Medicine, 143 Shimokasuya, Isehara 259-1143, Japan. E-mail: sgoto3@mac.com

All rights are reserved to the Japanese Circulation Society. For permissions, please e-mail: cj@j-circ.or.jp themselves may influence the functions of the platelets through stimulation of various receptors, such as proteaseactivated receptors (mostly PAR1, but also PAR422)23 ADP receptors ${ }^{14}$ integrins ${ }^{24}$ etc); however, these mechanisms are still not fully understood!,11,12

In the present study, we investigated the functional interrelationships between platelets and the coagulation system under arterial blood flow conditions, although the later is believed to be activated in vivo mostly at sites of blood stagnation.

\section{Methods}

Preparation of Blood Samples, Artificial Blood Flow Conditions, and Measurement of the $\left[\mathrm{Ca}^{2+}\right] \mathrm{i}$ of Platelets Incorporated in Thrombi

Venous blood samples were collected from 10 adult volunteers after obtaining their written informed consent. The investigation conformed with the principles of the Declaration of Helsinki and the study protocol was approved by the Internal Review Board of Tokai University. All of the study subjects ( 8 men, 2 women; age 28-44 years) were instructed to abstain from drugs known to interfere with platelet function during the month preceding the study. The blood specimens were immediately transferred into plastic tubes containing $1 / 10$ volume of the specific thrombin inhibitor argatroban (Mitsubishi Kagaku, Tokyo, Japan) at final concentrations ranging from 10 to $100 \mu \mathrm{mol} / \mathrm{L}$, to test for antithrombin effects on the formation of fibrin around the 
(1)

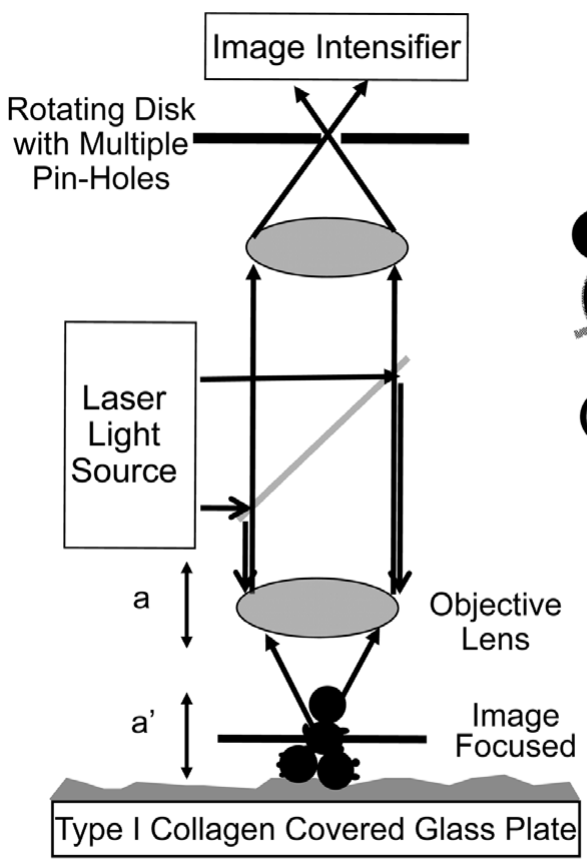

(2)

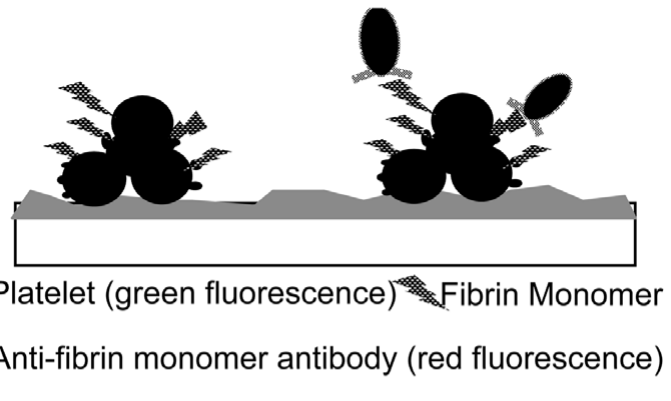

(3)

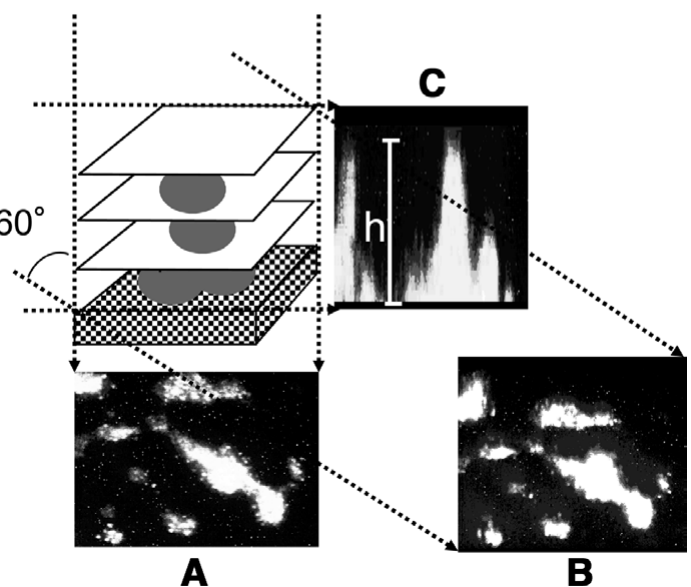

Figure 1. Multicolor and 3-dimensional (D) imaging of the thrombi formed under arterial blood flow conditions. Type I collagen fibrils were perfused with blood containing fluoresceinated platelets for $8 \mathrm{~min}$ at a wall shear rate of $1,500 / \mathrm{s}$ in a rectangular flow chamber. Thrombi formed on the collagen fibrils were visualized using both an epi-fluorescent multicolor video-microscope and the newly developed ultra-fast confocal laser microscope equipped with a piezo-motor control unit, as depicted schematically on the left-hand side. The activation of platelet-derived procoagulant activity was detected as the appearance of the fibrin monomer complex around the platelet thrombi visualized (in red), while platelets were visualized in green. The objective lens was moved up and down at a constant speed of $0.4 \mu \mathrm{m} / \mathrm{s}$ under the control of the piezo-motor control unit (a) to obtain scanning images of the platelet thrombi (a'). The sum of the scanning confocal images from the bottom to the top was projected on planes at 10-degree intervals relative to the $\mathrm{x}$-axis to obtain the 3-D projection images shown on the right-hand side, including the projections at 0 degrees (top view, $\mathbf{A}), 60$ degrees $(\mathbf{B})$ and 90 degrees (front view, C). The maximum height (h) of the platelet thrombi was calculated from the frontal projection image, as shown in $\mathbf{C}$.

A

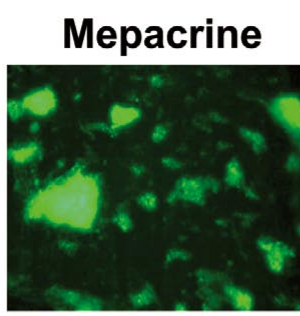

\section{Alexa Fluor 594

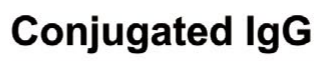

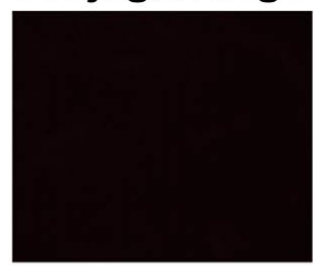
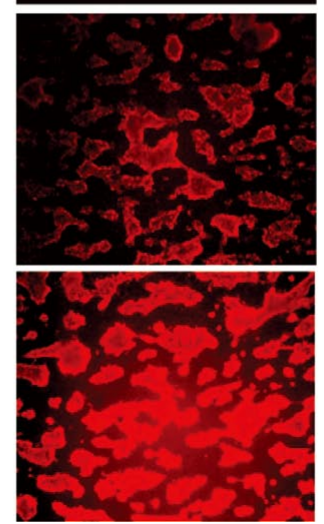

\section{Composite}
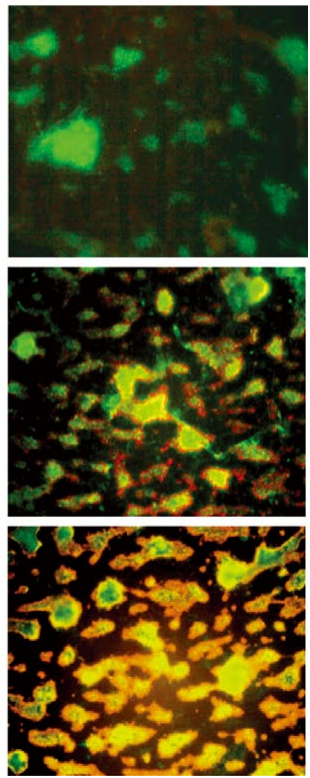

Figure 2. Specific detection of the fibrin monomer complex around the platelet thrombi. Platelet thrombi formed as a result of perfusion of the collagen fibrils with whole blood for $8 \mathrm{~min}$ (Left). Next, they were incubated with HEPES$\mathrm{NaCl}$ solution $(\mathrm{pH}$ 7.4) containing either 1 of the monoclonal antibodies, negative control antibody against thyroglobulin $(\mathrm{T} \gamma)$, human fibrin monomer complex (F-405), or positive control antibody against the platelet surface protein GPIb $\alpha$ (GUR20-5) at a concentration of $5 \mu \mathrm{g} / \mathrm{ml}$ for $15 \mathrm{~min}$. The specificity of the red fluorescence staining in the presence of antihuman fibrin monomer complex antibody (B) was confirmed by comparison with the staining results obtained with negative (A) and positive (C) control antibody. Superimposition of the green and red fluorescence staining images revealed the prominent presence of the fibrin monomer complex on the surface of the platelet thrombi. 

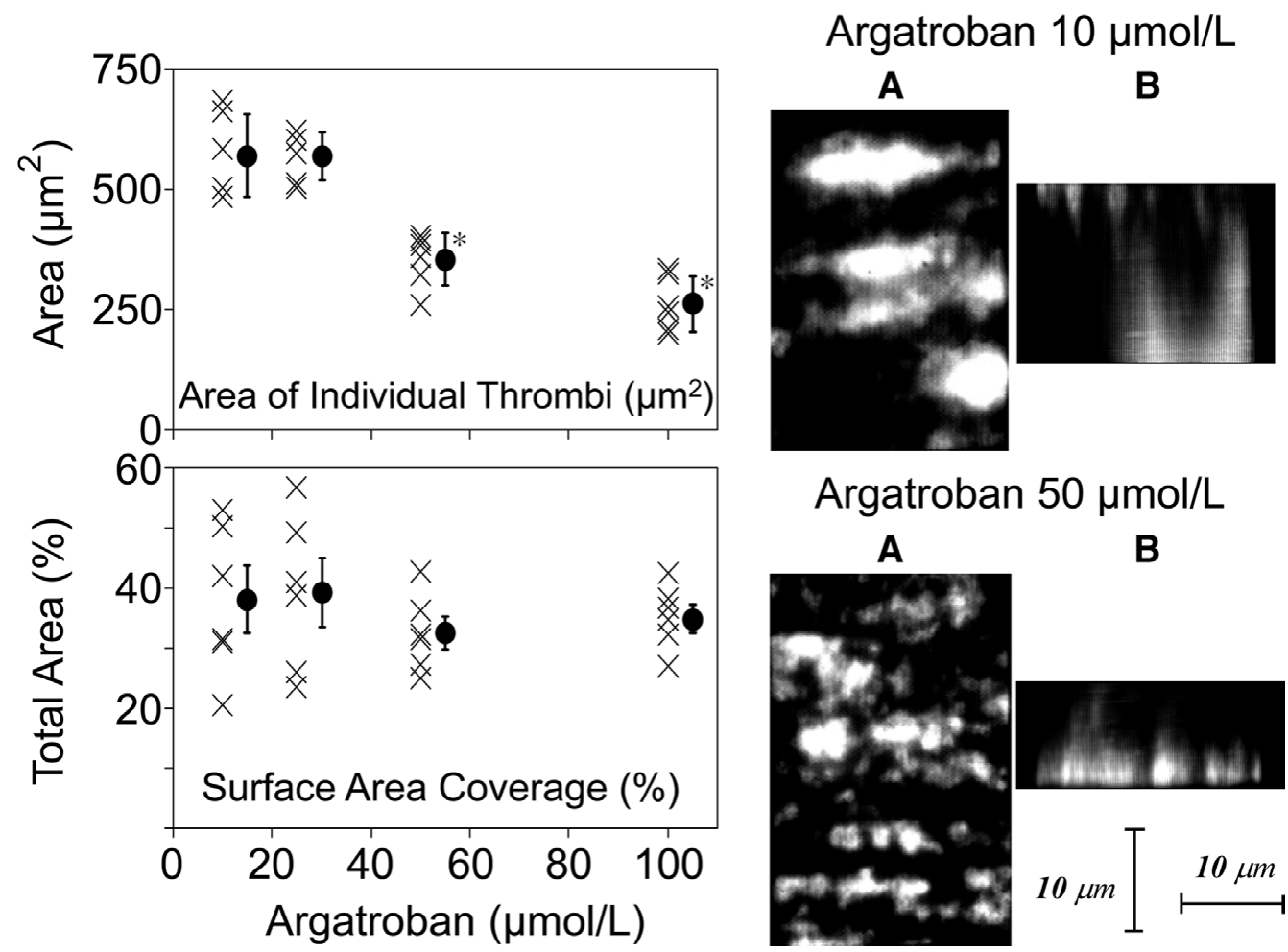

Figure 3. Relationship between inhibition of the function of thrombin and the 2- and 3-dimensional (D) growth of the platelet thrombi formed on the collagen fibrils by blood perfusion at a wall shear rate of $1,500 / \mathrm{s}$. Immobilized collagen fibrils in the rectangular flow chamber were perfused with blood samples containing the specific thrombin inhibitor argatroban $(10-100 \mu \mathrm{mol} / \mathrm{L})$ at varying final concentrations for $8 \mathrm{~min}$ at a wall shear rate of $1,500 / \mathrm{s}$. Projection images at $(\mathbf{A}) 0$ degrees along the $\mathrm{x}$-axis corresponding to the projection from the top of the thrombi and (B) 90 degrees along the $\mathrm{x}$-axis corresponding to the projection from the side of the thrombi. Quantitative results obtained from these 3-D images are summarized in Table 1. Quantitative surface area coverage by individual platelet thrombi, (Lower left) total area covered by the platelets. The results demonstrate the mean and standard error of 6 different experiments. *Significantly smaller value than that obtained by $8 \mathrm{~min}$ of perfusion of blood containing the lowest concentration of antithrombin tested in the study $(10 \mu \mathrm{mol} / \mathrm{L})$.

Table 1. Surface Area Coverage, Height and Volume of Individual Thrombi Formed on the Collagen Fibrils After 8 min of Perfusion of Blood Containing Various Concentrations of Antithrombin

\begin{tabular}{lcccc}
\hline \hline Argatroban $(\mu \mathrm{mol} / \mathrm{L})$ & 10 & 25 & 50 & 100 \\
\hline Area $\left(\mu \mathrm{m}^{2}\right)$ & $576.7 \pm-81.3$ & $555.0 \pm 181.4$ & $359.1 \pm 111.1^{*}$ & $256.7 \pm 47.3^{*}$ \\
Height $(\mu \mathrm{m})$ & $17.6 \pm 2.8$ & $14.9 \pm 1.6$ & $13.7 \pm 3.0^{*}$ & $10.4 \pm 0.6^{*}$ \\
Volume $\left(\mathrm{mm}^{3}\right)$ & $7.69 \pm 0.46$ & $6.61 \pm 1.96$ & $3.63 \pm 1.54^{*}$ & $1.67 \pm 0.75^{*}$ \\
\hline
\end{tabular}

*Value is significantly smaller than that obtained after $8 \mathrm{~min}$ of perfusion of blood containing the lowest concentration of argatroban used in the study $(10 \mu \mathrm{mol} / \mathrm{L})$. The same value is significantly smaller than that obtained in the presence of 25 or $50 \mu \mathrm{mol} / \mathrm{L}$ of argatroban.

platelet thrombi, on calcium signaling, and on the growth of the platelet thrombi25-27 Clinically relevant anticoagulants, including unfractionated heparin and low-molecular-weight heparin, were also tested, but the results could not be included because the blood coagulated during experiments.

For the experiments conducted to examine the growth of the thrombi and imaging of the platelet-derived procoagulant activity, platelets in whole blood samples were rendered fluorescent by the addition of mepacrine (Sigma Chemical Co, St Louis, MO, USA) ${ }^{25,27,28}$ For the experiments conducted to measure the intra-cytosolic calcium ion concentrations $\left(\left[\mathrm{Ca}^{2+}\right] \mathrm{i}\right)$, the platelets were loaded with the calciumsensitive dye, fluo-3AM, in accordance with a previously described procedure ${ }^{29}$ with slight modification ${ }^{26}$ Fluo-3 loaded platelets were re-suspended in homologous, initially separated platelet-poor plasma containing the antithrombin agent argatroban at a concentration of 10 or $100 \mu \mathrm{mol} / \mathrm{L}$. The hematocrit of the final cell suspension was adjusted to $40 \%$.

A rectangular flow chamber with its glass bottom coated with immobilized type I collagen fibrils was assembled as described previously! $1,25,28$ The experimental blood samples were aspirated into the chamber with a syringe pump (Harvard Apparatus, Holliston, MA, USA) for $8 \mathrm{~min}$ at a constant flow rate to obtain a wall shear rate of $1,500 / \mathrm{s}$ unless otherwise specified (limited number of experiments were conducted at shear rate 0 and $100 / \mathrm{s}$ ).

\section{Imaging of the Platelet Thrombi and Measurement of Platelet-Derived Procoagulant Activity}

The platelet thrombi were initially visualized using an inverted-stage epi-fluorescence video-microscopy system connected to a 480-nm excitation light source (DM IRB, 1RB-FLUO, Leica, Germany)! ${ }^{14,25}$ To quantify the 2-dimensional (D) growth of the platelet thrombi, both the surface 

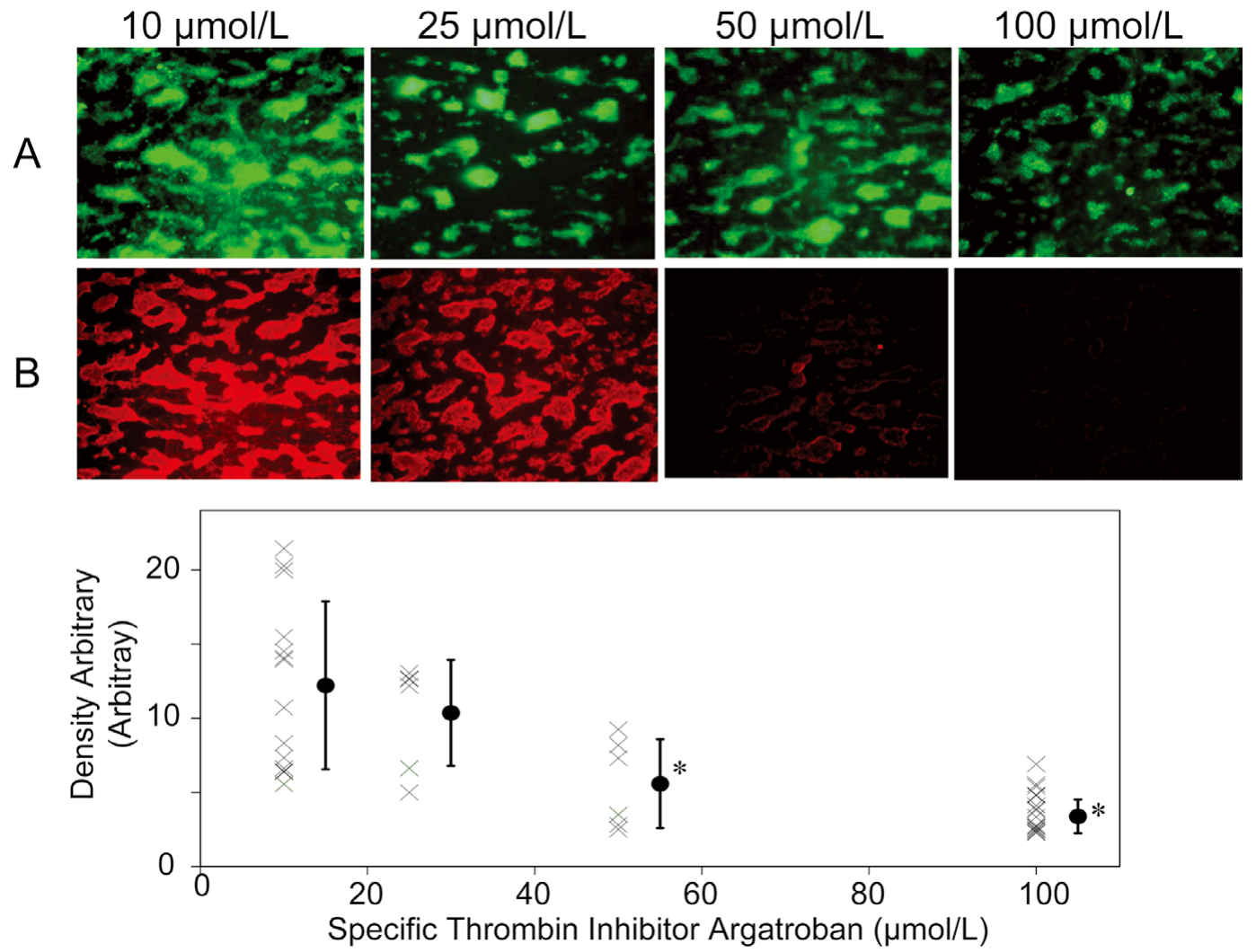

Figure 4. Relationship between functional inhibition of thrombin and the generation of the fibrin monomer complex around the platelet thrombi. The experiments were conducted in a similar manner as described in Figure 3. Dual-color fluorescence imaging was performed after washing with secondary antibody 3 times with $5 \mathrm{ml}$ of HEPES-NaCl solution ( $\mathrm{pH}$ 7.4). Fluoresceinated platelets (green), and fibrin monomers (red) were visualized using a barrier filter centered at the wavelengths of $527 \mathrm{~nm}(\mathbf{A})$ and $600 \mathrm{~nm}(\mathbf{B})$, respectively. Quantitative densitometry was performed to detect the total amount of fibrin monomers formed around the platelet thrombi, and the results are summarized in the lower panel.

area coverage of individual platelet thrombi $\left(\mu \mathrm{m}^{2}\right)$ and the total surface area coverage of the platelets $(\%)$ were calculated 25 The 3-D projection images of the platelet thrombi were also obtained with a fast confocal laser microscope equipped with a piezo-motor control unit, as described previously 26,30,31 (Figure 1). The 3-D projection images of the thrombi were obtained using the ImageJ $1.29 \mathrm{v}$ program (National Institutes of Health, Bethesda, MD, USA), as shown in Figure 126,30,31 The maximum height of the thrombi was calculated from a 90-degree (front) projection image, and the volume of each thrombus was derived by integration of the cumulative cross-sectional area occupied by the platelets in confocal sections obtained at $0.2-\mu \mathrm{m}$ intervals.

For imaging of the activation of the coagulation cascade on the surface of the platelet thrombi (platelet-derived procoagulant activity), HEPES-NaCl solution ( $\mathrm{pH} 7.4$ ) containing mouse-derived monoclonal antibody against the human fibrin monomer complex F- $405^{32}$ at a final concentration of $5 \mu \mathrm{g} / \mathrm{ml}$ was incubated with the platelet thrombi formed after $8 \mathrm{~min}$ of blood perfusion (Figure 1). The presence of the anti-fibrin monomer complex antibody on the platelet thrombi was detected using Alexafluor594conjugated goat-derived anti-mouse polyclonal IgG (Molecular Probes, Inc, OR, USA) at a final concentration of $10 \mu \mathrm{g} / \mathrm{ml}$. Both FITC-conjugated Annexin V (kindly provided by Dr Nomura, Kansai University, Osaka, Japan) and Alexafluor594-conjugated monoclonal antibody against tissue factor ATN-8 (kindly provided by Chugai, Co Ltd,
Gotenba, Japan) were used in some experiments to detect the distribution of negatively charged phospholipids and/or tissue factor on and/or around the platelet thrombi $i^{15,33}$ Dualcolor fluorescence imaging, to detect platelets as green and the fibrin monomer complex as red, was performed after the washing procedure with a barrier filter centered at wavelengths of $527 \mathrm{~nm}$ and $600 \mathrm{~nm}$, respectively (Figure 2). The specificity of detection of the fibrin monomer complex by this method was confirmed by comparison with the same concentration of iso-type matched negative and positive control IgG (GUR20-5: antibody against platelet GPIb $\alpha$, kindly provided by Dr Handa, Keio University, Tokyo, Japan) as shown in Figure 2. Quantitative densitometry was performed to measure the total amount of fibrin monomer complex formed around the platelet thrombi using the same method as that described previously to estimate the amount of platelet accumulation?

\section{Real-Time Imaging to Measure $\left[\mathrm{Ca}^{2+}\right]_{i}$ in Platelets Forming Thrombi Under Blood Flow Conditions}

The $\left[\mathrm{Ca}^{2+}\right]$ i of the platelets forming thrombi was measured using the same confocal microscopy system described previously ${ }^{29,26}$ but without the use of the piezo-motor control unit. Variations in the fluorescence intensity of the fluo-3AM-loaded platelets were converted into $\left[\mathrm{Ca}^{2+}\right]$ ising the equation:

$$
\left[\mathrm{Ca}^{2+}\right]_{\mathrm{i}}=\mathrm{Kd}(\mathrm{F}-\mathrm{Fmin}) /(\mathrm{Fmax}-\mathrm{F}),
$$


A

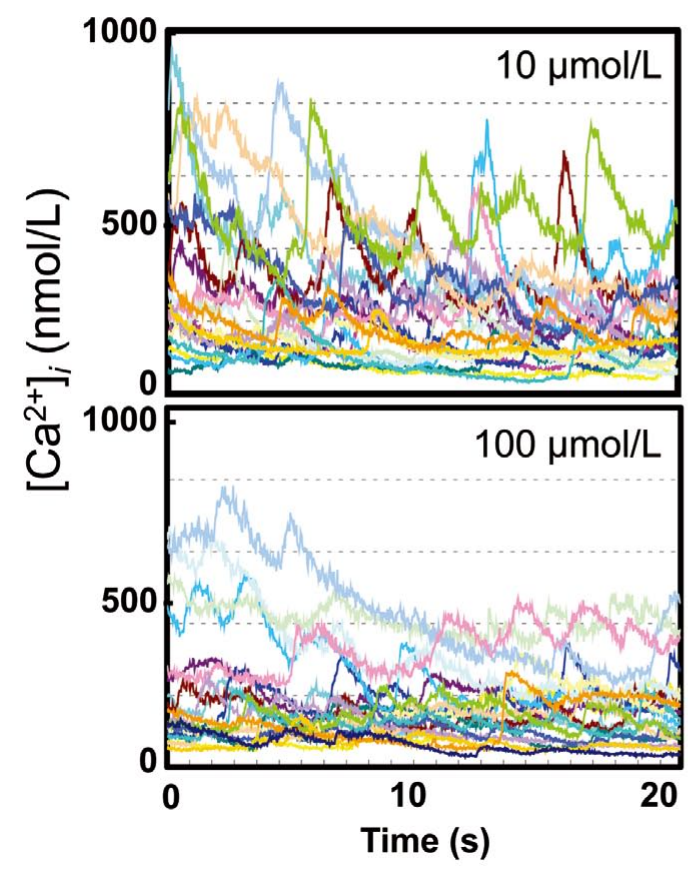

B

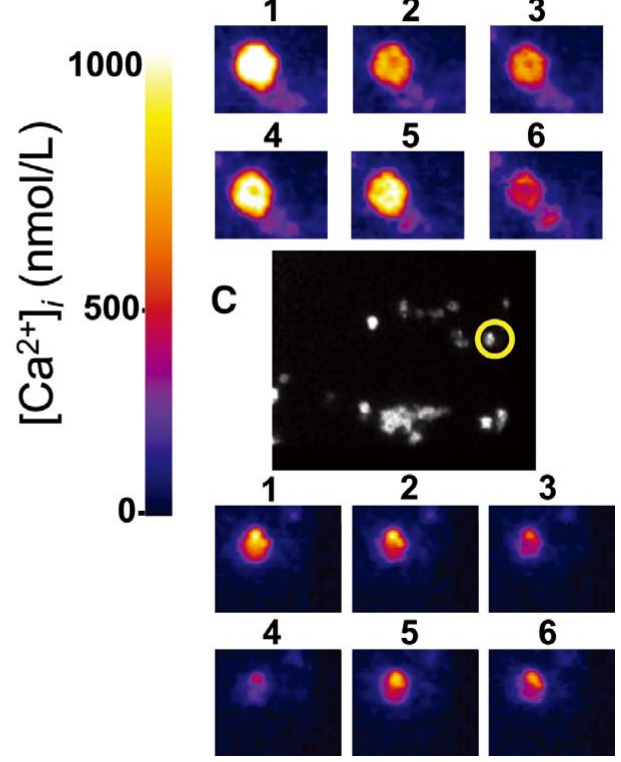

Figure 5. Changes in the $\left[\mathrm{Ca}^{2+}\right]$ i of the platelets forming the thrombi on the collagen fibrils under blood flow conditions. These experiments were conducted as described in Figure 3, except that the blood was replaced with a cell suspension containing fluo-3AM-loaded platelets, washed erythrocytes and homologous platelet-poor plasma with the specific thrombin inhibitor argatroban at 2 different concentrations, 10 and $100 \mu \mathrm{mol} / \mathrm{L}$. (Left: A) $\left[\mathrm{Ca}^{2+}\right]$ i of 10 randomly selected platelets recorded over a 10-s period beginning 2 min after the start of the blood perfusion, (Right) fluorescence images reflecting the $\left[\mathrm{Ca}^{2+}\right]_{\mathrm{i}}$ in individual platelets starting to adhere to the collagen surface in the presence of $10 \mu \mathrm{mol} / \mathrm{L}(\mathbf{B})$ and $100 \mu \mathrm{mol} / \mathrm{L}(\mathbf{C})$ of specific thrombin inhibitor argatroban. The results shown are representative of 4 different experiments.

where $\mathrm{Kd}$ is the dissociation constant of fluo-3AM in the interaction with $\mathrm{Ca}^{2+}$ (corresponding to $495 \mathrm{nmol} / \mathrm{L}$ at $25^{\circ} \mathrm{C}$ ) 34 $\mathrm{F}$ is the measured fluorescence intensity of a single platelet, Fmax is the fluorescence intensity of a single platelet treated with the $\mathrm{Ca}^{2+}$ ionophore A23187 $(10 \mu \mathrm{mol} / \mathrm{L}$; Sigma $)$ in the presence of $2 \mathrm{mmol} / \mathrm{L}$ calcium chloride, and Fmin is the fluorescence intensity of an unstimulated single platelet. To examine whether the changes in the $\left[\mathrm{Ca}^{2+}\right]$ i were related to trans-membrane entry or changes in the intracellular distribution, the effects of lanthanum chloride, a putative calciumchannel blocker, were tested. 26,35

\section{Statistical Analysis}

All numerical data are expressed as mean \pm SD, unless otherwise specified. The effect of various concentrations of argatroban on the growth of the platelet thrombi was tested by 1 -way analysis of variance (ANOVA). Differences between 2 groups of data were evaluated by Newman-Keuls test; $\mathrm{P}<0.05$ was considered to denote statistical significance.

\section{Results}

Inter-Relationship Between Inhibition of the Coagulation Cascade and Growth of Platelet Thrombi

As shown in Figure 3, the size of the individual thrombi that formed on the collagen fibrils was smaller after perfusion of blood containing higher concentrations of thrombin inhibitor. Quantitative analysis revealed that the area covered by individual platelet thrombi in the presence of thrombin inhibitor at concentrations of 50 and $100 \mu \mathrm{mol} / \mathrm{L}$ was significantly smaller than that formed in the presence of $10 \mu \mathrm{mol} / \mathrm{L}$ $(\mathrm{P}<0.05)$, as shown in Figure 3 and Table 1. The total surface area covered by the platelets was not significantly influenced by the concentration of thrombin inhibitor, indicating that a larger number of smaller thrombi formed in the presence of higher concentrations of thrombin inhibitor.

The 3-D projection imaging of the platelet thrombi using our newly developed confocal imaging technique revealed that the height and volume of individual thrombi formed after $8 \mathrm{~min}$ of perfusion of blood containing lower concentrations of thrombin inhibitor were larger than those formed after perfusion of blood containing higher concentrations of the same inhibitor (Figure 3, Table 1).

\section{Activation of the Coagulant Cascade Around Activated Platelets and the Role in Maintaining the Activated State of Platelets Incorporated Into Thrombi Under Arterial Blood Flow Conditions}

As shown in the upper panels of Figure 4, there was a larger amount of fibrin monomer complex, detected as red fluorescence, around the platelet thrombi formed in the presence of lower concentrations of thrombin inhibitor. A similar distribution of FITC-conjugated Annexin V could be detected under the same conditions, whereas neither tissue factor nor tissue-factor-bearing microparticles, a homogeneous distribution of which could be detected by our imaging system, were detected around the platelet thrombi (data not shown). Quantitative densitometric analysis, shown 

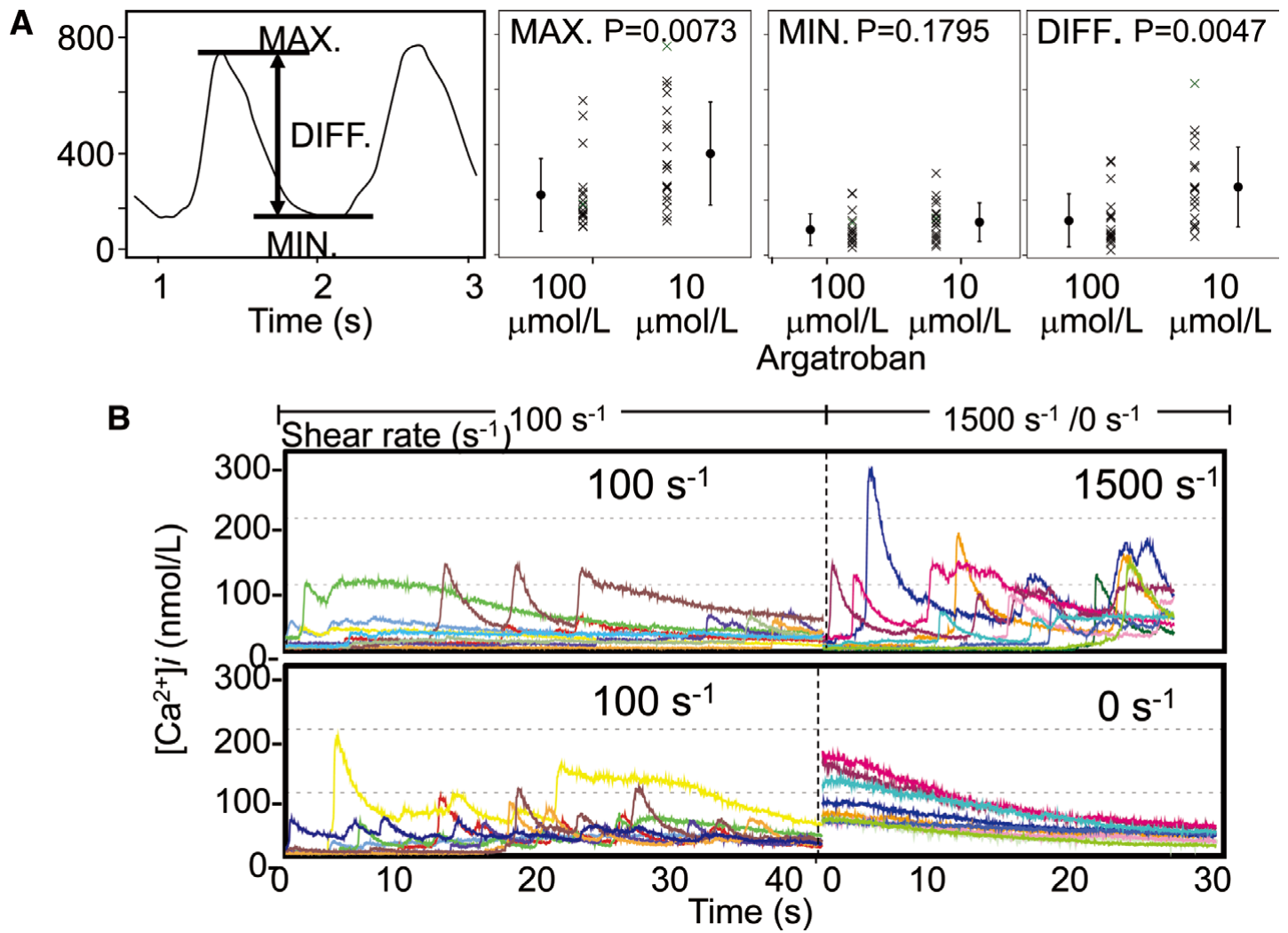

Figure 6. Quantitative results of $\left[\mathrm{Ca}^{2+}\right]$ i and changes in the $\left[\mathrm{Ca}^{2+}\right]$ i of the platelets forming the thrombi on the collagen fibrils under various shear rates. (A) These experiments were conducted as described in Figure 6. The minimum (MIN.), maximum (MAX.) and difference (DIFF.) between the minimum and maximum $\left[\mathrm{Ca}^{2+}\right]$ i defined in the upper right panel were calculated for 20 randomly selected platelets in 4 different experiments. The mean values and the SD are shown. (B) These experiments were conducted as described in Figure 6, except that the shear rate was changed as shown in the upper panel. Each line represents the $\left[\mathrm{Ca}^{2+}\right]_{i}$ in individual platelets under shear rates shown above. Results shown are the 4 different experiments in the presence of $100 \mu \mathrm{mol} / \mathrm{L}$ of specific thrombin inhibitor argatroban.

in the lower panel of Figure 4, demonstrates the dosedependent inhibitory effects of thrombin inhibitor on the generation of the fibrin monomer complex around the platelet thrombi formed under arterial blood flow conditions.

The $\left[\mathrm{Ca}^{2+}\right] \mathrm{i}$ of the platelets adhering to the collagen fibrils is shown in Figure 5A. A cyclic increase in the $\left[\mathrm{Ca}^{2+}\right]_{\mathrm{i}}$ occurred in the majority of individual platelets adhering to the immobilized collagen fibrils, although the strength and cycle length of the oscillations were not homogeneous. The addition of the putative calcium-channel blocker, lanthanum chloride, at a final concentration of $1 \mathrm{mmol} / \mathrm{L}$ to the blood samples completely blocked these cyclic increases in the $\left[\mathrm{Ca}^{2+}\right]^{26}$ (data not shown). There was, however, a tendency for the maximum increase in the $\left[\mathrm{Ca}^{2+}\right] \mathrm{i}$ to be greater in the presence of lower concentrations of thrombin inhibitor. Indeed, quantitative analysis of 20 randomly selected platelets in 4 different experiments revealed that both the maximum value and the differences between the maximum and minimum values of $\left[\mathrm{Ca}^{2+}\right] \mathrm{i}$ were significantly higher in the presence of $10 \mu \mathrm{mol} / \mathrm{L}$ argatroban than the corresponding values in the presence of $100 \mu \mathrm{mol} / \mathrm{L}$ of the same inhibitor (Figure 6A). We also demonstrated that the cyclic increase in the $\left[\mathrm{Ca}^{2+}\right]_{i}$ is shear rate dependent and disappears at a shear rate of 0 (Figure 6B).

\section{Discussion}

In the present study, we demonstrated activation of the coagulation cascade around platelet thrombi formed under arterial blood flow conditions, as evidenced by the appearance of fibrin monomer complexes around the platelet thrombi. We have also demonstrated that the cyclic increase in $\left[\mathrm{Ca}^{2+}\right]_{i}$ in each platelet incorporated into the thrombi, which is assumed to represent the sum of the activation signals of the platelet and has been shown to be influenced by shear rate and the presence of specific thrombin inhibitor, positively correlates with the 3-D growth, especially in the z-section, of the platelet thrombi. Our experimental results suggest an important regulatory role of thrombin generated on the surface of activated platelets as a result of the procoagulant activity in both the formation of fibrin around the platelets and the maintenance of the activated state of platelets incorporated into thrombi so that the platelet thrombi remain stable and, at least in our experimental conditions, the calcium-sensitive phospholipid scramblase ${ }^{36,37}$ is activated to continue further expression of procoagulant phospholipid on the platelet thrombi (Figure 7) 38,39

Our experimental results with human blood samples were in complete agreement with in vivo animal experiments published previously $3^{3}$ Our findings fundamentally serve to confirm those animal experimental results, except that we used human blood in an in vitro setup without blood vessels. Obviously, our model does not pose any problems related to species differences, which is important in understanding the regulatory role of the activation of the coagulant cascade in the 3-D growth of platelet thrombi, because it is well 


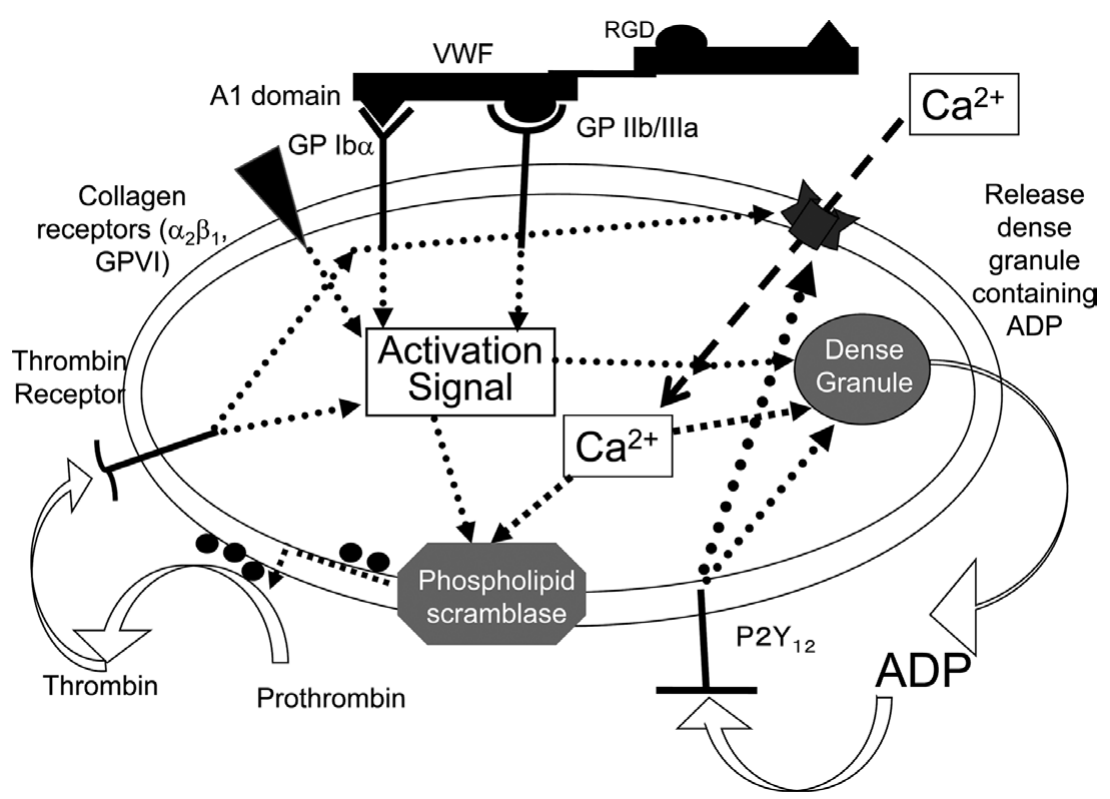

Figure 7. Regulatory role of platelet-derived procoagulant activity on the continuous activation of platelet and thrombus growth. Platelets, once they interact with subendothelial matrix such as collagen or von Willebrand factor (VWF) 48,49 activated to release ADP-containing dense granules. Next, the released ADP stimulates ADP receptors ( $\mathrm{P} 2 \mathrm{Y}_{1}$ and $\mathrm{P} 2 \mathrm{Y}_{12}$ ). As previously demonstrated, continuous stimulation of $\mathrm{P}_{2} \mathrm{Y}_{12}$ results in a cyclic increase in $\left[\mathrm{Ca}^{2+}\right] \mathrm{i}$, which activates many $\mathrm{Ca}^{2+}$-dependent enzymes, such as phospholipid scramblase. Activation of that enzyme increased the expression of procoagulant negatively charged phospholipid, which supports conversion of prothrombin to thrombin on the surface of the activated platelet. Thrombin generated on the surface of activated platelets further activates the platelet through thrombin receptors. known that the thrombin receptor, a major possible regulator in humans, is a different moiety in mice. Indeed, proteaseactivated receptor, 40 which is the most important functional receptor of thrombin in humans, is not expressed on mouse platelets 23 Perhaps the main limitations of our blood perfusion model, however, are the differences in the blood flow conditions and the matrix exposed to the blood stream we used from an in vivo setting. Moreover, we had to use at least a minimal amount of anticoagulant to maintain blood fluidity during our experiments, which could influence the generation and function of thrombin. Our experiments cannot assess the clinically relevant, low dose of anticoagulant (not only argatroban, but also unfractionated heparin, low-molecular-weight heparin, etc). Moreover, our method is not applicable for assessing the effects of various antiplatelet agents on platelet-derived procoagulant activity because it requires the formation of large-enough platelet thrombi on collagen fibrils, which is inhibited by antiplatelet agents. Our methodology to detect fibrin monomer is not sensitive enough to detect small changes at various shear rates. We are attempting overcome this limitation by improving imaging tool, but could not provide relevant results in the current report.

Despite these limitations, the thrombi that formed on the collagen fibrils in our experimental model, and comprised both activated platelets and fibrin, were basically the same as the pathological arterial thrombi causing myocardial infarction, although the latter contain a larger amount of insoluble fibrin fibrils:,3 Nevertheless, we believe that our main findings give new insights into the key role of activated platelet-derived procoagulant activity in the growth of thrombi. We propose this begins with activation of the platelets accumulating at a site of endothelial injury under blood flow conditions, followed by the appearance of activatedplatelet-derived procoagulant activity ${ }^{41}$ and the generation of thrombi on the membrane surface of activated platelets, even under arterial flow conditions, which results in both local fibrin fibril formation and in continuous activation of the platelets forming thrombi by repetitive stimulation of thrombin receptors, causing an increase in $\left[\mathrm{Ca}^{2+}\right]$ i to activate phospholipid scramblase ${ }^{37}$ and further enhancing platelet-derived procoagulant activity,2 as well as maintaining the stability of platelet thrombi for the development of large arterial occlusive thrombi (Figure 7) ${ }^{26}$ There is an interesting previous publication showing that mice that are deficient in phospholipid scramblase do not express bleeding problems ${ }^{36}$ In this context, regulation of phospholipid scramblase might be a possible target of antiplatelet agents with least bleeding complications. Further investigation is awaited.

Nonetheless, our experimental results provide little information regarding the mechanism of induction of the plateletderived procoagulant activity, the details of which are still to be clarified ${ }^{43,44}$ Previous reports have demonstrated the importance of the surface expression of negatively charged phospholipids, mostly phosphatidylserine, ${ }^{45}$ which can be detected by Annexin V binding, ${ }^{15}$ and its appearance was confirmed in our study in association with activation of the coagulation cascade on the surface of the activated platelets. It is also known that increased $\left[\mathrm{Ca}^{2+}\right] \mathrm{i}$, which was shown in our study, especially in the presence of low concentrations of thrombin inhibitor (Figure 6), plays certain important roles in the activation of phospholipid scramblase ${ }^{26}$ resulting in surface exposure of phosphatidylserine. 46 Accordingly, our results showing an increase in the $\left[\mathrm{Ca}^{2+}\right]$ i of the platelet forming thrombi not only indicate the activated state of the platelets, but also the induction of procoagulant activity resulting in the appearance of the fibrin monomer complex. Indeed, a previous report demonstrated that factor IXa binding to platelet and generation of activated factor Xa was prevented by the putative $\mathrm{Ca}^{2+}$ channel-blocker of lanthanum chloride ${ }^{47}$ Unlike in vivo animal experiments ${ }^{33,48}$ or atherothrombosis in humans, 2,3,6 our experiments did not include tissue factor originating from the vascular wall or ruptured atheroma. Thus, tissue factor, if it played a role in the generation of fibrin in our experiments, is limited to a blood-borne one. 48 The limitation to our experiments that a small amount of anticoagulant is required makes it impossible to assess whether the lower amount of fibrin fibril formation we observed is because of a lack of vessel-related tissue factor or represents the effects of antithrombin. The fact that we could detect neither soluble tissue factor nor accumulation of tissue-factor-bearing microparticles around the platelet thrombi in our experiments, despite the significant amount of tissue factor detected on the surface of the monocytes 
that were eventually incorporated into the thrombi (data not shown), causes us to speculate that the role of tissue factor may not have been important in the initiation of the activation of the coagulation cascade around the platelet thrombi, at least in our flow chamber system. Nevertheless, some investigators have demonstrated the initiation of the coagulation cascade by phospholipids and Factor XI on erythrocytes, even in the absence of tissue factor ${ }^{49}$ which may be relevant to our present results. In any case, further investigations are required to elucidate the correct mechanism of the initiation of the activation of the coagulation cascade on the surface of the platelet thrombi under blood flow conditions.

In conclusion, in experiments using human blood under artificial blood flow conditions, we have demonstrated, using a 2-color imaging system, the local production of fibrin around the surface of activated platelets (activated plateletderived procoagulant activity) forming thrombi, even in the presence of specific antithrombin agents in the blood in amounts sufficient to maintain the fluidity of the blood during the experiments. We have shown a positive relationship between the magnitude of the increase in the $\left[\mathrm{Ca}^{2+}\right]$ i of the platelets incorporated within thrombi and the amount of fibrin monomer complex generated around them. We have also demonstrated the role of increased $\left[\mathrm{Ca}^{2+}\right]$ i of the platelets incorporated within the thrombi in maintaining the stability of the platelet thrombi and, consequently, their 3-D growth. The recognition of these functional links between the activation of the platelets and local activation of the coagulation cascade around them may provide new insight into the crucial role of platelet-derived procoagulant activity in the regulation of arterial thrombus growth. Our results suggest a regulatory role of both the activation of the coagulation cascade on the surface of platelet thrombi and the local generation of thrombin, even under arterial blood flow conditions, not only in the local generation of fibrin fibrils around platelet thrombi but also in maintaining the stability of platelet thrombi and further enhancing procoagulant activity related to the activation of phospholipid scramblase following an increase in the $\left[\mathrm{Ca}^{2+}\right]$ i of the platelets forming thrombi. We have thus shown a close functional linkage between the activation of platelets and the coagulation system even under arterial blood flow conditions.

\section{Acknowledgments}

We gratefully acknowledge the contribution of the staff of Tokai University Educational and Research Support Center. This work was supported in part by a Grant-in-Aid for Scientific Research in Japan (15590771, 17590764, 19590871), Tokai University School of Medicine, Project Research 2006, a grant from the Vehicle Racing Commemorative Foundation, a grant for the Leading Project and Next Generation of the Integrated Biological Simulator Developing Program Supported by the Ministry of Education and Science, Sports and Culture, Japan, and a grant for the nextgeneration supercomputer Research and Development program supported by RIKEN, and a grant for Regulatory Medicine supported by the Ministry of Health, Labor and Welfare, Japan, to S.G.

\section{References}

1. Ruggeri ZM. Platelets in atherothrombosis. Nat Med 2002; 8: $1227-1234$.

2. Hoshiba Y, Hatakeyama K, Tanabe T, Asada Y, Goto S. Co-localization of von Willebrand factor with platelet thrombi, tissue factor and platelets with fibrin, and consistent presence of inflammatory cells in coronary thrombi obtained by an aspiration device from patients with acute myocardial infarction. J Thromb Haemost 2006; 4: 114-120.

3. Yamashita A, Sumi T, Goto S, Hoshiba Y, Nishihira K, Kawamoto R, et al. Detection of von Willebrand factor and tissue factor in plateletsfibrin rich coronary thrombi in acute myocardial infarction. $A m J$ Cardiol 2006; 97: 26-28.
4. Goto S. Understanding the mechanism and prevention of arterial occlusive thrombus formation by anti-platelet agents. Curr Med Chem Cardiovasc Hematol Agents 2004; 2: 149-156.

5. Ma YQ, Qin J, Plow EF. Platelet integrin $\alpha$ (IIb) $\beta$ : Activation mechanisms. J Thromb Haemost 2007; 5: 1345-1352.

6. Mackman N, Tilley RE, Key NS. Role of the extrinsic pathway of blood coagulation in hemostasis and thrombosis. Arterioscler Thromb Vasc Biol 2007; 27: 1687-1693.

7. Gailani D, Renne T. Intrinsic pathway of coagulation and arterial thrombosis. Arterioscler Thromb Vasc Biol 2007; 27: 2507-2513.

8. Libby P, Aikawa M. Stabilization of atherosclerotic plaques: New mechanisms and clinical targets. Nat Med 2002; 8: 1257-1262.

9. Goto S. Propagation of arterial thrombi: Local and remote contributory factors. Arterioscler Thromb Vasc Biol 2004; 24: 2207-2208.

10. Gawaz M, Langer H, May AE. Platelets in inflammation and atherogenesis. J Clin Invest 2005; 115: 3378-3384.

11. Wagner DD, Burger PC. Platelets in inflammation and thrombosis. Arterioscler Thromb Vasc Biol 2003; 23: 2131-2137.

12. Strukova SM. Role of platelets and serine proteinases in coupling of blood coagulation and inflammation. Biochemistry (Mosc) 2004; 69: $1067-1081$.

13. Gear AR, Camerini D. Platelet chemokines and chemokine receptors: Linking hemostasis, inflammation, and host defense. Microcirculation 2003; 10: 335-350.

14. Goto S, Tamura N, Eto K, Ikeda Y, Handa S. Functional significance of adenosine 5'-diphosphate receptor (P2Y(12)) in platelet activation initiated by binding of von Willebrand factor to platelet GP Iba induced by conditions of high shear rate. Circulation 2002; 105: 2531-2536.

15. Dachary-Prigent J, Pasquet JM, Freyssinet JM, Nurden AT. Calcium involvement in aminophospholipid exposure and microparticle formation during platelet activation: A study using $\mathrm{Ca}^{2+}$-ATPase inhibitors. Biochemistry 1995; 34: 11625-11634.

16. Tamura N, Yoshida M, Ichikawa N, Handa M, Ikeda Y, Tanabe T, et al. Shear-induced von Willebrand factor-mediated platelet surface translocation of the CD40 ligand. Thromb Res 2002; 108: 311-315.

17. Youssef AA, Chang LT, Sheu JJ, Lee FY, Chua S, Yeh KH, et al. Association between circulating level of CD40 ligand and angiographic morphologic features indicating high-burden thrombus formation in patients with acute myocardial infarction undergoing primary coronary intervention. Circ J 2007; 71: 1857-1861.

18. Henn V, Slupsky JR, Grafe M, Anagnostopoulos I, Forster R, MullerBerghaus $\mathrm{G}$, et al. CD40 ligand on activated platelets triggers an inflammatory reaction of endothelial cells. Nature 1998; 391: 591 594.

19. Hagihara M, Higuchi A, Tamura N, Ueda Y, Hirabayashi K, Ikeda Y, et al. Platelets, after exposure to a high shear stress, induce IL-10producing, mature dendritic cells in vitro. J Immunol 2004; 172: $5297-5303$.

20. Miyazaki Y, Nomura S, Miyake T, Kagawa H, Kitada C, Taniguchi $\mathrm{H}$, et al. High shear stress can initiate both platelet aggregation and shedding of procoagulant containing microparticles. Blood 1996; 88: $3456-3464$

21. Reininger AJ, Heijnen HF, Schumann H, Specht HM, Schramm W, Ruggeri ZM. Mechanism of platelet adhesion to von Willebrand factor and microparticle formation under high shear stress. Blood 2006; 107: $3537-3545$.

22. Dorsam RT, Tuluc M, Kunapuli SP. Role of protease-activated and ADP receptor subtypes in thrombin generation on human platelets. J Thromb Haemost 2004; 2: 804-812.

23. Coughlin SR. Thrombin signalling and protease-activated receptors. Nature 2000; 407: 258-264.

24. Andre P, Prasad KS, Denis CV, He M, Papalia JM, Hynes RO, et al. CD40L stabilizes arterial thrombi by a beta 3 integrin-dependent mechanism. Nat Med 2002; 8: 247-252.

25. Goto S, Tamura N, Handa S, Arai M, Kodama K, Takayama H. Involvement of glycoprotein VI in platelet thrombus formation on both collagen and von Willebrand factor surfaces under flow conditions. Circulation 2002; 106: 266-272.

26. Goto S, Tamura N, Ishida H, Ruggeri ZM. Dependence of platelet thrombus stability on sustained glycoprotein III/IIIa activation through adenosine 5'-diphosphate receptor stimulation and cyclic calcium signaling. J Am Coll Cardiol 2006; 47: 155-162.

27. Sakakibara M, Goto S, Eto K, Tamura N, Isshiki T, Handa S. Application of ex vivo flow chamber system for assessment of stent thrombosis. Arterioscler Thromb Vasc Biol 2002; 22: 1360-1364.

28. Savage B, Saldivar E, Ruggeri ZM. Initiation of platelet adhesion by arrest onto fibrinogen or translocation on von Willebrand factor. Cell 1996; 84: 289-297.

29. Nesbitt WS, Giuliano S, Kulkarni S, Dopheide SM, Harper IS, 
Jackson SP. Intercellular calcium communication regulates platelet aggregation and thrombus growth. J Cell Biol 2003; 160: 11511161.

30. Goto S, Tamura N, Ishida $\mathrm{H}$. Ability of anti-glycoprotein IIb/IIIa agents to dissolve platelet thrombi formed on a collagen surface under blood flow conditions. J Am Coll Cardiol 2004; 44: 316-323.

31. Genka C, Ishida $\mathrm{H}$, Ichimori $\mathrm{K}$, Hirota $\mathrm{Y}$, Tanaami T, Nakazawa $\mathrm{H}$. Visualization of biphasic $\mathrm{Ca}^{2+}$ diffusion from cytosol to nucleus in contracting adult rat cardiac myocytes with an ultra-fast confocal imaging system. Cell Calcium 1999; 25: 199-208.

32. Hamano A, Tanaka S, Takeda Y, Umeda M, Sakata Y. A novel monoclonal antibody to fibrin monomer and soluble fibrin for the detection of soluble fibrin in plasma. Clin Chim Acta 2002; 318: $25-32$.

33. Falati S, Gross P, Merrill-Skoloff G, Furie BC, Furie B. Real-time in vivo imaging of platelets, tissue factor and fibrin during arterial thrombus formation in the mouse. Nat Med 2002; 8: 1175-1181.

34. Merritt JE, McCarthy SA, Davies MP, Moores KE. Use of fluo-3 to measure cytosolic $\mathrm{Ca}^{2+}$ in platelets and neutrophils. Loading cells with the dye, calibration of traces, measurements in the presence of plasma, and buffering of cytosolic $\mathrm{Ca}^{2+}$. Biochem J 1990; 269: $513-$ 519.

35. Friedman H, Meir S, Rosenberger I, Halevy AH, Kaufman PB, Philosoph-Hadas S. Inhibition of the gravitropic response of snapdragon spikes by the calcium-channel blocker lanthanum chloride. Plant Physiol 1998; 118: 483-492.

36. Zhou Q, Zhao J, Wiedmer T, Sims PJ. Normal hemostasis but defective hematopoietic response to growth factors in mice deficient in phospholipid scramblase 1. Blood 2002; 99: 4030-4038.

37. Zhou Q, Zhao J, Stout JG, Luhm RA, Wiedmer T, Sims PJ. Molecular cloning of human plasma membrane phospholipid scramblase A protein mediating transbilayer movement of plasma membrane phospholipids. J Biol Chem 1997; 272: 18240-18244.

38. Goto S. Understanding the mechanism of platelet thrombus formation under blood flow conditions and the effect of new antiplatelet agents. Curr Vasc Pharmacol 2004; 2: 23-32.

39. Goto S, Salomon DR, Ikeda Y, Ruggeri ZM. Characterization of the unique mechanism mediating the shear-dependent binding of soluble von Willebrand factor to platelets. J Biol Chem 1995; 270: $23352-$ 23361.

40. Vu TK, Hung DT, Wheaton VI, Coughlin SR. Molecular cloning of a functional thrombin receptor reveals a novel proteolytic mechanism of receptor activation. Cell 1991; 64: 1057-1068.

41. Goto S, Tamura N, Li M, Handa M, Ikeda Y, Handa S, et al. Different effects of various anti-GPIIb-IIIa agents on shear-induced platelet activation and expression of procoagulant activity. J Thromb Haemost 2003; 1: 2022-2030.

42. Andersen H, Greenberg DL, Fujikawa K, Xu W, Chung DW, Davie EW. Protease-activated receptor 1 is the primary mediator of thrombin-stimulated platelet procoagulant activity. Proc Natl Acad Sci USA 1999; 96: 11189-11193.

43. Bahou WF, Scudder L, Rubenstein D, Jesty J. A shear-restricted pathway of platelet procoagulant activity is regulated by IQGAP1. J Biol Chem 2004; 279: 22571-22577.

44. Goto S. Factor XIa as a possible new target of antithrombotic therapy. J Thromb Haemost 2006; 4: 1494-1495.

45. Sims PJ, Wiedmer T. Unraveling the mysteries of phospholipid scrambling. Thromb Haemost 2001; 86: 266-275.

46. Keuren JF, Wielders SJ, Ulrichts H, Hackeng T, Heemskerk JW, Deckmyn H, et al. Synergistic effect of thrombin on collagen-induced platelet procoagulant activity is mediated through protease-activated receptor-1. Arterioscler Thromb Vasc Biol 2005; 25: 1499-1505.

47. London FS, Marcinkiewicz M, Walsh PN. PAR-1-stimulated factor IXa binding to a small platelet subpopulation requires a pronounced and sustained increase of cytoplasmic calcium. Biochemistry 2006; 45: 7289-7298.

48. Falati S, Liu Q, Gross P, Merrill-Skoloff G, Chou J, Vandendries E, et al. Accumulation of tissue factor into developing thrombi in vivo is dependent upon microparticle P-selectin glycoprotein ligand 1 and platelet P-selectin. J Exp Med 2003; 197: 1585-1598.

49. Iwata H, Kaibara M. Activation of factor IX by erythrocyte membranes causes intrinsic coagulation. Blood Coagul Fibrinolysis 2002; 13: $489-496$. 